\title{
НАУЧНЫЕ ПРЕДСТАВЛЕНИЯ Я.А. ПОНОМАРЁВА О ЦЕНТРАЛЬНОМ ЗВЕНЕ ПСИХОЛОГИЧЕСКОГО МЕХАНИЗМА ПОВЕДЕНИЯ И ИХ РАЗВИТИЕ (К 100-ЛЕТИЮ СО ДНЯ РОЖДЕНИЯ УЧЁНОГО) ${ }^{1}$
}

\author{
Т.В. Галкина \\ Институт психологии РАН
}

\begin{abstract}
Аннотация: В статье, посвященной 100-летию со дня рождения выдающегося психолога, глубокого философа и мыслителя, блестящего экспериментатора, талантливого человека Якова Александровича Пономарёва, представлены основные результаты его научного творчества, имеющие общепсихологическое и общенаучное значение. Рассмотрены научные представления Пономарёва о психологическом механизме поведения и его иентральном звене - способности действовать «в уме» (СДУ). В своих трудах Пономарёв неоднократно возвращался к рассмотрению и обсуждению понятий «психологический механизм», «центральное звено психологического механизма поведения» и подчеркивал, что их изучение должно опираться на основные приниипь системного подхода. В статье показана эволюиия содержания и иенность введенного в психологию понятия СДУ. Данная способность является базовой для развития других познавательных способностей. СДУ - это фундаментальная специфическая составляющая человеческой психики, важнейший показатель умственного развития. Пономарёвым разработана спечиальная методика диагностики уровня развития СДУ, выделено пять этапов развития этой способности и показано, что каждый из них качественно отличается от другого, но при этом пластично с ним связан и плавно переходит в него. Представлены результаты исследований учеников и последователей Пономарёва, свидетельствующие о возможностях экстраполячии научных идей ученого в отношении способности действовать «в уме», как иентрального звена психологического механизма поведения, из области психологии творчества в область психологии личности и общей психологии в иелом.
\end{abstract}

Ключевые слова: Я.А. Пономарёв, психологический механизм, иентральное звено психологического механизма поведения, психология творчества, методология, взаимодействие, развитие, закон ЭУС («этапь-уровни-ступени)», интуиция, логика, внутренний план действий, способность действовать «в уме» (СДУ), типы знания

\section{YA. A. PONOMAREV'S SCIENTIFIC CONCEPTS ABOUT THE CENTRAL LINK OF THE PSYCHOLOGICAL MECHANISM OF BEHAVIOR AND THEIR DEVELOPMENT (FOR THE 100-TH ANNIVERSARY OF HIS BIRT)}

\author{
T.V. Galkina \\ Institute of Psychology, Russian Academy of Sciences
}

\begin{abstract}
The article is dedicated to the 100-th anniversary of the birth of the outstanding psychologist, deep philosopher and thinker, brilliant experimenter, talented person Yakov Aleksandrovich Ponomarev. It presents the main results of his scientific work having general-psychological and general-scientific significance. Ponomarev's scientific ideas about the psychological mechanism of behavior
\end{abstract}

${ }^{1}$ Государственное задание № 0159-2020-0006. 
Научные труды Московского гуманитарного университета

2020 № 5

and its central link - the ability to act «in the mind» (AAM) are considered. In his writings Ponomarev repeatedly returned to the consideration and discussion of such concepts as "psychological mechanism», "the central link of the psychological mechanism of behavior» and emphasized that their study should be based on the basic principles of the systems approach. The article shows the evolution of the content and value of the AAM concept. This ability is basic for the development of other cognitive abilities. AAM is a fundamental specific component of the human psyche, the most important indicator of mental development. Ponomarev created the special technique for diagnosing the level of AAM development and then identified five developmental stages of this ability and showed that each of them is qualitatively different from the other, but at the same time it is plastically connected with it and smoothly passes into it. The article presents the studies' results of Ponomarev's students and followers, indicating the possibilities of extrapolating the scientist's scientific ideas regarding the ability to act «in the mind» as the central link of the psychological mechanism of behavior from the field of creative psychology to the field of personality psychology and general psychology.

Keywords: Ya.A. Ponomarev, psychological mechanism, the central link of the psychological mechanism of behavior, psychology of creativity, methodology, interaction, development, PLS («phases-levels-stages») principle, intuition, logic, inner plan of action, ability to act «in the mind» (AAM), types of knowledge

В этом году отмечается 100-летие со дня рождения Я.А. Пономарёва, который занимает особое место в отечественной психологии. Философско-психологическая система научных представлений Якова Александровича Пономарёва талантливого человека, выдающегося психолога, блестящего экспериментатора, глубокого философа и мыслителя, имеет не только общепсихологическое, но и общенаучное значение. Он внес неоценимый вклад в развитие различных сфер психологической науки, ее истории и методологии. На протяжении многих лет, начиная фактически с 50-60-х гг. ХХ столетия (Пономарёв, 1960) и до настоящего времени, Пономарёв - безусловный лидер в области психологии творчества, но, пожалуй, не меньшее значение его работы имеют и для методологии психологической науки в целом (Пономарёв, 1957, 1959, 1983, 2006, 2010 и др.). Яков Александрович всегда тяготел к разработке глобальных научных проблем психологии и философии, что видно уже из названий его самых ранних работ. Например, самая первая статья Пономарёва, опубликованная в 1957 г., называется «К вопросу о психологических механизмах взаимоотношения чувственного и логического познания». Название другой статьи, вышедшей двумя годами позже - «О взаимодействии и развитии...» (Пономарёв, 1957, 1959). Пономарёв позиционировал себя в психологическом сообществе ученым, разрабатывающим проблематику творчества. Однако он рассматривал эту область психологического знания, как своеобразный «экспериментальный полигон», «просто как область приложения» (Пономарёв, 2006, 2010; Журавлёв, Галкина, 2010: 34) для предложенных и разрабатываемых им новаторских и оригинальных идей, связанных с методологическим принципом взаимодействия, структурно-уровневой концепцией развития психики, законом ЭУС («этапы-уровни-ступени»), идеей двухполюсной организации Мироздания, этапов (типов) развития научного знания и др.) (Журавлёв, Галкина, 2016).

Теория Пономарёва в процессе его научного творчества претерпела серьез- 
ные изменения, что связано с постоянной глубокой рефлексией и переосмыслением ученым полученных им данных, как в блестящих экспериментальных исследованиях, так и в результате глубоких теоретических размышлений.

Основные результаты многолетних исследований Я.А. Пономарёва одновременно можно рассматривать и как «краеугольные камни» его философско-психологической теории.

Кратко изложим их в соответствии с логикой развития теории Пономарёва: открытие феномена неоднородности результата действия человека и «побочного» продукта деятельности; выявление психологического механизма интуиции и введение категории взаимодействия; учение о психологическом механизме решения творческих задач, творчества и поведения, а также его центральном звене - внутреннем плане действий - ВПД (позже - способности действовать «в уме» - СДУ); открытие факта «подобия форм», принципа, а затем универсального закона ЭУС; учение о фазах творчества и структурных уровнях его организации; введение категории рефлексии и выявление ядра психологического механизма группового творчества; теория этапов (типов) развития психологического (научного) знания и разработка идеи экспериментальной методологии, как атрибута действенно-преобразующего типа знания (Галкина, Журавлёв, 2016a, 2019, 2020).

Значимость всех положений философско-психологической системы научных представлений Пономарёва для теории, методологии и практики социогуманитарных наук трудно переоценить, однако, далеко не все идеи ученого нашли продолжение в научных исследованиях и внедрены в общественную практику. Наблюдаемое в последнее время повышение интереса к трудам Я.А. Пономарёва говорит об осознании научным сообществом необходимости переосмысления многих идей ученого в соответствии с реалиями современной науки и практики. Отметим, что некоторые положения теории Пономарева, имеющие общепсихологическое значение, являются достаточно разработанными, имеется также и опыт внедрения их в общественную практику. Это относится, в первую очередь, к учению о психологическом механизме решения творческих задач, творчества и поведения человека в целом, а также к центральному звену этого механизма - внутреннему плану действий - ВПД (позже - способности действовать «в уме»-СДУ). Именно об этом важнейшем положении теории Пономарёва и его развитии в современных научных исследованиях, а также о его использовании в сфере образования пойдет речь в этой статье.

Понятия «механизм», «психологический механизм» давно превратились в своеобразные шаблоны, стали «затёртыми». Их применение часто приводит к тому, что содержательный смысл этих понятий ускользает от исследователей. Я.А. Пономарёв в своих трудах неоднократно возвращался к рассмотрению и обсуждению понятия «психологический механизм», подчеркивая, что его изуче- 
ние должно опираться на основные принципы системного подхода (Ломов, 1984; Пономарёв, 2006, 2010). В рамках системного подхода анализ психологического механизма должен включать: изучение структуры, системного (уровневого) строения, особенностей развития и функционирования изучаемого объекта, его взаимосвязей и места в общей системе психических процессов, явлений. Одним из основных требований является изучение уровневой организации исследуемого объекта в динамике (т.е. в плане развития или функционирования). Таким образом, психологический механизм - это то, что позволяет раскрыть особенности психического отражения, регуляции, общения, взаимодействия людей, оставаясь на психологическом уровне. Анализ психологического механизма представляет собой конструктивный подход к изучаемому объекту в том случае, если мы не теряем качественную особенность этих объектов, не подменяем психологический анализ каким-либо другим (социологическим, физиологическим и т.д.).

Согласно принципу системности, изучаемые явления рассматриваются с позиции их целостности, которая не сводится к простой сумме составляющих ее частей, а задает их связь и взаимодействие, иерархическое строение, при этом на передний план выдвигается логика целостности, синтеза, взаимопереходов и взаимовключений. Исследования, направленные на изучение психологических механизмов тех или иных явлений, феноменов, при соблюдении вышеперечисленных требований, являются, по мнению Пономарёва, перспективными и способствующими переходу эмпирического типа знания к новому (тогда еще гипотетически выделенному ученым, но теперь реально существующему) действенно-преобразующему типу научного знания (Пономарёв, 1983, 2006; Галкина, Журавлёв, 2016b, 2018).

Пономарёв, давая определение понятию «психологический механизм», пишет, что под психологическим механизмом понимается складывающийся на врожденной основе инвариант содержания приобретаемого (накопленного) индивидом опыта (Пономарёв, 2006: 188-189, 2010: 264).

Работа, направленная на выявление психологического механизма сначала интуиции, творческого мышления и творчества, затем - индивидуального познания, а позже - и всего поведения, в итоге привела ученого к представлению о гносеологическом механизме общественного познания в целом (Пономарёв, 2006: 227).

Согласно концепции Пономарёва, центральным звеном психологического механизма творческого мышления, творчества и поведения человека является внутренний план действия (ВПД) или способность действовать «в уме» (СДУ) (Пономарёв, 1967, 1976a, 1976b).

В работах Пономарёва можно проследить эволюцию содержания и значимости понятия «внутренний план действий» (позже - «способность действовать “в уме"») от специфической особенности человеческого интеллекта - важнейшей характеристики умственного развития ребенка (Пономарёв, 1967) - через цен- 
тральное звено психологического механизма творческого мышления, интеллекта, творчества - к центральному звену психологического механизма поведения человека в целом (Пономарёв, 1976a, 1976b, 1983, 2006 и др.) ${ }^{2}$

Ценность введенного в психологию понятия СДУ состоит в том, что оно имеет более широкое содержание, чем другие термины, обозначающие какой-либо когнитивный процесс. СДУ - фундаментальная специфическая составляющая человеческой психики и важнейший показатель умственного развития. Эта способность необходима для успешного осуществления практически любой деятельности, поведения и взаимодействия людей, поскольку лежит в основе прогнозирования, целеполагания, преобразования объекта деятельности в соответствии с замыслом, а также разработки целенаправленных и целесообразных способов достижения цели. Без достаточно высокого уровня развития СДУ невозможно решать творческие задачи, поскольку данная способность обеспечивает успех в нахождении интуитивных решений, их вербализации и формализации (Пономарёв, 1976а, 1976b и др.; Галкина, 1986, 2010, 2011 и др.; Галкина, Журавлёв, 2016b и др.; Журавлёв, Галкина, 2010, 2016 и др.).

Пономарёвым была разработана специальная методика «Игра в классики», позволяющая диагностировать уровень (этап) развития внутреннего плана действий или иначе - способности действовать «в уме» (Пономарёв, 1967, 1976а). Принципиальная схема этой методики заключается в следующем. Испытуемого обучают какому-либо конкретному действию и дают ему такую задачу, для решения которой необходимо построить систему действий, состоящую из ряда тождественных элементов. Любым элементом этой системы является то действие, которому в начале эксперимента и обучали испытуемого. Однако построению самой системы действий его не учили. Предлагаемые задачи испытуемый может решать по-разному: при опоре на наглядно выраженные условия, т.е. действуя непосредственно предметами, или же действуя представлениями предметов, т.е. «в уме». С этой целью поле действия кодируется, т.е. каждой клеточке присваивается свое «имя». Испытуемый выучивает предложенный код и правила перемещения по полю. Его задача - перемещать «в уме» сообразно задаче воображаемый предмет в воображаемом поле словесно заданной ему координатной сетки. Обычно предлагается несколько серий задач. Каждая последующая серия предъявляет более высокие требования к возможностям действовать «в уме» (Пономарёв, 1967, 1976а, 1976b; Галкина, 1986, 2010, 2011 и др.).

В результате многочисленных исследований Пономарёв выявил существование пяти (гипотетически - шести) этапов развития способности действовать «в уме». Эти этапы качественно отличаются один от другого, но в то же время пластично взаимосвязаны и плавно переходят друг в друга. Первый этап является фоновым, исходным - здесь дети не могут действовать «в уме» в масштабах

\footnotetext{
2 Подробно об эволюции понятий ВПД и СДУ см. Галкина, 2010, 2011 и др.
} 
требований, предъявляемых конкретной методикой «Игра в классики». На втором этапе развития СДУ задачи решаются, но только во внешнем плане, а во внутреннем плане возможна лишь репродукция уже готового решения. На третьем этапе появляется способность манипулировать представлениями вещей, но еще не удается в достаточной мере подчинить эти манипуляции требованиям словесно поставленной задачи. На четвертом этапе такое подчинение оказывается возможным: найденное решение кладется в основу плана повторных действий, каждое из которых теперь строго соотносится с требованиями задачи. Пятый этап характеризуется полным развитием СДУ: с самого начала «в уме» строится план, вся программа и система действий (Пономарёв, 1967, 1976a, 1976b, 2006 и др.).

Занимаясь разработкой проблем психологии творчества, методологии и теории психологии, а также умственного развития детей, Пономарёв фактически проводил свои экспериментальные исследования по двум направлениям:

1) исследовал закономерности решения творческой задачи интеллектуально развитыми взрослыми, у которых способность действовать «в уме» достигла полного (или почти полного) развития - (Пономарев, 1960, 2010);

2) изучал особенности развития и формирования этой способности у детей (Пономарёв, 1967, 1976b).

Сопоставление результатов этих исследований привело ученого к открытию, что формы поведения детей на разных этапах развития способности действовать «в уме» оказались подобными формам поведения взрослых на соответствующих фазах (ступенях) решения творческих задач. Это позволило Пономарёву сделать вывод, что этапы онтогенеза способности действовать «в уме» не исчезают бесследно, а преобразуются в структурные уровни организации механизма, с помощью которого решаются творческие задачи. Таким образом, Пономарёв увидел, что этапы развития ребенка в онтогенезе, формы его поведения подобны формам поведения взрослого человека, решающего творческую задачу. Это сопоставление результатов позволило Пономареву сформулировать сначала принцип, а затем универсальный закон ЭУС («этапь--уровни-ступени»).

Согласно этому закону любой психический процесс (любая система) в ходе своего становления проходит определенные этапы развития, которые не исчезают бесследно, а превращаются в структурные уровни его организации и выступают в виде функциональных ступеней решения творческих задач или любых проблем в новых (или экстремальных) для человека ситуациях. В общем виде эти функциональные ступени решения творческих задач являются функциональными ступенями дальнейших развивающих взаимодействий (Пономарёв, 2006; Галкина, Журавлёв, 2016а, 2016b, 2019 и др.).

Открытие закона ЭУС дало возможность Пономарёву выработать структурно-уровневое представление о психологическом механизме творчества и поведения (Пономарёв, 1976а). Он пишет, что результаты проведенных им опытов 
Научные труды Московского гуманитарного университета

2020 № 5

с детьми и взрослыми позволяют схематически изобразить центральное звено психологического механизма интеллекта, творчества и поведения в целом в виде двух проникающих одна в другую сфер. Внешние грани этих сфер можно представить как абстрактные пределы мышления - интуитивный и логический. «Снизу» таким пределом оказывается интуитивное мышление, где действия выполняются преимущественно во внешнем плане, они неосознанны, невербализованы, эмоциональны, процесс и продукт здесь не расчленены. «Сверху» находится логическое мышление человека. Действия здесь строятся по жесткому внутреннему плану, они осознаются, вербализованы, процесс и продукт оказываются расчлененными.

Важнейшей особенностью данного психологического механизма является единство логического и интуитивного, осознаваемого и неосознаваемого, рационального и эмоционального, прямого и побочного продуктов деятельности. Согласно Пономарёву, логическое и интуитивное существуют у человека только вместе в виде двух взаимопроникающих сфер (Пономарёв, 1976a, 1976b и др.). Таким образом, психологический механизм творчества и поведения представлен иерархией этапов - уровней развития способности действовать «в уме», которую ученый стал считать центральным звеном психологического механизма поведения человека в целом (Пономарёв, 1983, 2006, 2010: 232-274; Галкина, Журавлёв, 2016b).

К описанию и форме представления схемы психологического механизма творчества, поведения (позже Пономарёв называет это и «механизмом психологического познания») ученый обращается неоднократно вплоть до последних дней своей жизни, пытаясь довести до совершенства рисунок и формулировку схемы «механизма психологического познания» (Пономарёв, 2010: 270). Уже из названия схемы видна экстраполяция взглядов ученого из психологии творчества и умственного развития ребенка («механизм индивидуального познания») на уровень общепсихологический и методологический (Галкина, Журавлёв, 2016b).

Фактически развитие научных идей Я.А. Пономарёва в отношении способности действовать «в уме» началось с дипломного, а затем диссертационного исследования автора данной статьи. Исследование особенностей формирования и функционирования психологического механизма решения задач на самооценку (выполненное в 1986 г. под научным руководством Якова Александровича Пономарёва) показало, что высокий уровень развития СДУ, обеспечивая успех в решении широкого круга задач, в том числе и творческих, играет важнейшую роль также и в решении специфических задач на самооценку и оценку других людей (Галкина, 1986). Оказалось, что разным уровнем развития способности действовать «в уме» можно объяснить, в частности, и значительные различия, наблюдаемые в способах оценивания и самооценивания. Были выявлены следующие интересные закономерности. В случае высокого уровня развития данной способности (IV-V этапы развития СДУ) задачи на оценку и самооценку решаются подобно 
интеллектуальным (логическим, нетворческим) задачам. В случае же среднего уровня развития (III этап развития СДУ) при определенных дополнительных условиях (в частности, при наличии высокой степени активности в раннем детстве, тесного эмоционального контакта с родителями, прошлого опыта решения личностных задач) самооценочные задачи решаются испытуемыми как творческие, т.е. в них присутствует как интуитивный, так и логический компоненты. Низкий уровень развития СДУ (I-II этапы) тормозит как интеллектуальный, так и творческий процесс решения различных задач на самооценку. Таким образом, экспериментально было установлено, что существует зависимость между этапом развития СДУ и особенностями, как процесса, так и результатов решения рассматриваемых задач: чем выше этап, тем больше успешных (адекватных, вербализованных) решений. Уровень развития СДУ, влияя на процесс решения различных задач на самооценку, определяет особенности формирования и функционирования механизма саморегуляции личности. Это свидетельствует о том, что способность действовать «в уме» не только важнейшая характеристика интеллектуального развития, но и центральное звено психологического механизма решения задач на самооценку (Галкина, 2010, 2011 и др.; Галкина, Журавлёв, 2016b).

Научные представления Пономарёва о способности действовать «в уме» получили дальнейшее развитие во многих исследованиях, выполненных последователями Якова Александровича и непосредственно под научным руководством автора этой статьи (Галкина, Алексеева, 1991; Хуснутдинова, 1993; Пономарёв, Пастернак, 1995; Кононенко, 1997, 2004; Пономарёв, Галкина, Кононенко, 1997; Хайкина, 1998; Пастернак, 2001; и др.).

Как указывалось выше, Пономарёв для определения этапа развития способности действовать «в уме» разработал специальную методику «Игра в классики», которую он использовал в своих работах (Пономарёв, 1967, 1976a, 1976b). Эта же методика (частично модифицированная в целях конкретных эмпирических исследований) была использована и в работах учеников Т.В. Галкиной и последователей Я.А. Пономарёва.

Способность действовать «в уме», являясь базовой для развития других познавательных способностей, определенным образом связана и с развитием креативности личности, и ее специальных способностей. Этот результат был получен в исследованиях Л.Г. Хуснутдиновой (Алексеевой) (1993) и М.А. Кононенко $(1997,2004)$.

Наши совместные исследования с Л.Г. Хуснутдиновой были посвящены изучению речемыслительной креативности у московских школьников 12-15 лет. В целях исследований нами переведена с английского языка и впервые апробирована на русскоязычной выборке методика C. Медника - RAT, направленная на диагностику вербальной креативности (Галкина, Алексеева, 1991; Хуснутдинова, 
Научные труды Московского гуманитарного университета

2020 № 5

1993). Были получены результаты, говорящие о взаимосвязи речемыслительной креативности и СДУ. Эта зависимость имеет своеобразный пороговый характер: высокий уровень развития СДУ оказался необходимым, но недостаточным условием высокого уровня речемыслительной креативности (Галкина, 2010).

Л.Г. Хуснутдиновой были также получены интересные результаты о взаимосвязи уровня развития СДУ и школьной успеваемости. Было выявлено, что существует определенное несоответствие между показателями школьной успеваемости и уровнями развития СДУ и речемыслительной креативности личности: высокая академическая успеваемость далеко не всегда положительно коррелирует с высоким уровнем развития СДУ и креативности. Был сделан вывод, что в существующем виде школьная оценка не выполняет в достаточной степени функций индикатора и стимула развития интеллектуальных и творческих способностей (Хуснутдинова, 1993, Галкина, 2010).

Исследование М.А. Кононенко было посвящено изучению роли общей СДУ в развитии «музыкальной» СДУ и музыкальной одаренности, а также успешности музыкально-исполнительской деятельности (Кононенко, 1997, 2004; Пономарёв, Галкина, Кононенко, 1997). Исследование проводилось с учащимися музыкальных школ 6-10 лет. Предметом исследования было соотношение общих и специальных компонентов одаренности у юных музыкантов. В качестве общих компонентов музыкальной одаренности рассматривались важнейшие составляющие общей творческой одаренности - СДУ и креативность; в качестве специальных - «музыкальные» СДУ и креативность, которые проявляются в музыкально-исполнительской деятельности.

Для решения поставленных в исследовании задач были разработаны новые методики диагностики СДУ, креативности и успешности в музыкально-исполнительской деятельности. Особенно интересна методика диагностики «музыкальной» СДУ. Она построена аналогично классической методике Пономарева «Игра в классики», направленной на диагностику общей СДУ. Суть новой методики диагностики «музыкальной» СДУ заключается в том, что учащимся предлагается найти решение «музыкально-технической» задачи, а именно подобрать правильную аппликатуру (пальцовку) для заданного музыкального звукоряда с указанными номерами пальцев в его начале и конце. За счет варьирования диапазона звукоряда (от одной до трех октав) достигается возможность уточнения объема действий испытуемого (Кононенко, 1997). Эта методика была разработана М.А. Кононенко еще при жизни Я.А. Пономарёва и высоко оценена им (и как психологом, и как человеком, имеющим музыкальное образование и хорошо играющим на фортепьяно).

Результаты проведенного М.А. Кононенко исследования подтвердили гипотезу о существовании взаимосвязи между общими и специальными компонентами одаренности в музыкально-исполнительской деятельности. Это позволило го- 
ворить о том, что СДУ является единой способностью, которая может проявляться независимо от сферы деятельности и от характера материала, с которым производятся умственные действия (Пономарёв, Галкина, Кононенко, 1997). Уровень развития СДУ связан с особенностями таких сторон музыкально-исполнительской деятельности, как чтение нот с листа, освоение музыкального произведения, техника игры на музыкальном инструменте (Кононенко, 2004).

Отметим, что учение Пономарева о способности действовать «в уме», как центральном звене психологического механизма поведения человека, открывает широкие возможности в области практической психологии образования и педагогики в плане развития не только общей способности (отвечающей за возможности формирования всех специфически человеческих знаний, умений и навыков), но и специальных способностей (в частности, музыкальных), креативности и одаренности.

Еще одним экспериментальным подтверждением положения о том, что СДУ является центральным звеном психологического механизма поведения, стало исследование, проведенное М.В. Хайкиной, направленное на изучение взаимосвязи между уровнем развития способности действовать «в уме» и особенностями развития речи и двигательных навыков. Испытуемыми в данном исследовании были дети дошкольного возраста (5-6,5 лет) (Хайкина, 1998; Галкина, 2010).

Полученные результаты показали, что среди детей 5-6,5 лет обнаружена иная картина развития СДУ, чем в младшем школьном возрасте. Среди них были дети только с I-III этапами диагностируемой способности, в младшем школьном возрасте же разброс индивидуальных различий в уровне развития СДУ шире: от I до $\mathrm{V}$ этапов. В возрасте 5-6,5 лет большинство детей достигает середины и конца I, а также начала II этапов развития СДУ. Всесторонний анализ особенностей развития речи и двигательных навыков детей с началом I этапа развития данной способности показал, что этот этап является некоторым отклонением от нормы, случаем определенной задержки развития СДУ (Хайкина, 1998).

М.В. Хайкиной выявлена взаимосвязь между уровнем развития СДУ и особенностями развития речи. Отметим, что особенно ярко эта взаимосвязь проявляется в повышении уровня развития грамматического строя речи, способности адекватно подбирать слова, связно строить высказывания и правильно описывать пространственные отношения между предметами у детей с высоким уровнем развития СДУ, по сравнению с детьми с задержкой развития СДУ (Галкина, 2010).

В исследовании Хайкиной обнаружена также взаимосвязь между уровнем развития СДУ и особенностями развития двигательных навыков: отмечено повышение уровня развития и качества мелкой моторики у детей с высоким уровнем развития СДУ (Хайкина, 1998).

Исследование Н.А. Пастернак продолжило разрабатываемую нами линию по преодолению разрыва между интеллектуальными и личностными 
аспектами психологического исследования Объектом данного исследования были студенты московских вузов в возрасте 19-22 лет (Пастернак, 2001). Полученные результаты позволили сделать несколько интересных выводов. Так, оказалось, что с ростом уровня развития СДУ расширяются интеллектуальные возможности личности. Об этом, в частности, свидетельствует увеличение количества успешно решенных задач в интеллектуальных тестах испытуемыми с более высокими этапами развития СДУ. Это в свою очередь говорит в пользу понимания СДУ как содержательного эквивалента понятия «общий интеллект» (Галкина, 2010).

Н.А. Пастернак было выявлено также, что с ростом уровня развития СДУ: увеличивается дифференцированность при анализе слов обыденного языка, обозначающих черты личности; возрастает мера обобщенности в формировании образа «должного поведения»; на формирование самооценки все большее влияние начинает оказывать не частное содержание действий, а субъективная оценка того, какие нормы наиболее предпочтительны в конкретной ситуации (Пастернак, 2001).

В исследовании, проведенном совместно Н.А. Пастернак с Я.А. Пономарёвым, было показано влияние способности действовать «в уме» на данные психологического тестирования (Пономарёв, Пастернак, 1995). В исследовании участвовали московские школьники 16-18 лет. Оказалось, что испытуемые с высоким уровнем развития СДУ с большей вероятностью, чем испытуемые с низким уровнем, дают социально желательные ответы в тестах. Испытуемые с низким уровнем развития СДУ способны адекватно оценить собственные действия, связанные с реальным поведением в конкретной ситуации; оценка же предполагаемого поведения для них затруднена; в ситуации фрустрации они чаще обвиняют другого человека. При самооценке по личностным характеристикам они считают себя более активными; при оценке собственного поведения видят себя плохо контролирующими и более конформными людьми, по сравнению с испытуемыми с более высоким уровнем развития СДУ (Пономарёв, Пастернак, 1995; Галкина, 2010).

В этих исследованиях было показано, что СДУ является системообразующим фактором, объединяющим в себе как когнитивные, так и личностные характеристики поведения человека в их неразрывном единстве, а уровень развития этой способности связан с процессом социальной адаптации личности к социокультурным условиям, существующим в обществе (Галкина, 2010).

Полученные во многих исследованиях эмпирические результаты подтверждают гипотетическое предположение Якова Александровича Пономарёва о том, что способность действовать «в уме» - это не только общая и базовая способность для развития других познавательных способностей и важнейшая характеристика интеллектуального развития, как он считал в своих ранних работах (Пономарёв, 1967), но и центральное звено психологического механизма поведения человека в целом, о чем Пономарев писал в своих более поздних трудах (Пономарёв, 2006, 2010: 232-275). 
Проведенные нами, нашими учениками и коллегами исследования продемонстрировали одну из возможностей экстраполяции научных взглядов Пономарева в отношении способности действовать «в уме» (СДУ) из области психологии творчества в общую психологию и психологию личности (Галкина, 2010, 2011; Галкина, Журавлёв, 2016a, 2016b и др.).

Яков Александрович Пономарёв своей жизнью и научным творчеством подтвердил одно из основных положений созданной им философско-психологической теории о том, что высокий уровень развития способности действовать «в уме» (а он имел наивысший уровень ее развития) оказывает значительное влияние на различные стороны жизнедеятельности человека, стимулируя его к творческому решению самых разнообразных задач и позволяя продуцировать новые идеи и знания, ведущие к открытиям, влияющим на развитие науки и общества (Журавлёв, Галкина, 2016).

Научное наследие Я.А. Пономарёва богато новыми оригинальными идеями, глубокими философскими размышлениями, методологическими и методическими находками. Интерес к творчеству этого неординарного психолога, философа и методолога, переосмысление его научного наследия с учетом современных особенностей и проблем социогуманитарных наук позволит поднять на новый уровень методологического обобщения сделанные Пономарёвым разработки и наметить пути их дальнейшего развития и внедрения в различные социальные практики.

\section{СПИСОК ЛИТЕРАТУРЫ}

Галкина Т.В. (1986) Психологический механизм решения задач на самооценку. Дис. ... канд. психол. наук. М.: Институт психологии РАН.

Галкина Т.В. (2010) Развитие концепции Я.А. Пономарева о центральном звене психологического механизма поведения // Психология интеллекта и творчества: Традиции и инновации. М.: Институт психологии РАН. С. 22-34.

Галкина Т.В. (2011) Самооценка как процесс решения задач: системный подход. М.: Институт психологии РАН.

Галкина Т.В., Алексеева Л.Г. (1991) Диагностика и развитие креативности // Развитие и диагностика способностей / Отв. ред. В.Н. Дружинин, В.Д. Шадриков. М.: Наука. С. 170-178.

Галкина Т. В., Журавлёв А.Л. (2016а) Развитие научного творчества Я.А. Пономарёва // Психологический журнал. Т. 37. № 1. С. 16-25.

Галкина Т.В., Журавлёв А.Л. (2016b) К вопросу о психологическом механизме творчества и поведения: анализ и развитие концепции Я.А. Пономарёва // Человеческий фактор: проблемы психологии и эргономики. № 1 (77). С. 21-26.

Галкина Т.В., Журавлёв А.Л. (2018) Проблема типов психологического знания в трудах Я.А. Пономарева // Психологическое знание: Современное состояние и перспективы развития. М.: Институт психологии РАН. С. 246-274. 
Галкина Т.В., Журавлёв А.Л. (2019) Основные научные идеи Я.А. Пономарёва в области теории и методологии психологии // Ярославский педагогический вестник. №2. (107). С. 73-81.

Галкина Т.В., Журавлёв А.Л. (2020) Вклад Я.А. Пономарёва в развитие методологических и теоретических вопросов психологической науки (к 100-летию со дня рождения) // Психологический журнал. Т. 41. № 6. С. 5-13.

Журавлёв А.Л., Галкина Т.В. (2010) Основные вехи жизненного пути и научного творчества Я.А. Пономарёва // Я.А. Пономарёв. «Психика и интуиция. Неопубликованные материалы, стихи, рисунки и фотографии. М.: ООО «ТИД. “Арис"». C. 6-54.

Журавлёв А.Л., Галкина Т.В. (2016) Философско-психологическая система научных представлений Я.А. Пономарёва: истоки, основные положения, перспективы // История отечественной и мировой психологической мысли: судьбы ученых, динамика идей, содержание концепций. М.: Институт психологии РАН. С. 264-279.

Кононенко М.А. (1997) Экспериментальное исследование способности действовать «в уме» у юных пианистов // Когнитивное обучение: современное состояние и перспективы. М.: Институт психологии РАН. С. 115-124.

Кононенко М.А. (2004) Соотношение общих и специальных компонентов одаренности в музыкально-исполнительской деятельности. Дис...канд. психол. наук. М.: Институт психологии РАН.

Ломов Б.Ф. (1984) Методологические и теоретические проблемы психологии. М.: Наука.

Пастернак Н.А. (2001) Способность действовать «в уме» как механизм произвольной регуляции поведения личности. Дис. ... канд. психол. наук. М.: Институт психологии РАН.

Пономарёв Я.А. (1957) К вопросу о психологических механизмах взаимоотношения чувственного и логического познания // Доклады АПН РСФСР. № 4. С. 67-73.

Пономарёв Я.А. (1959) О взаимодействии и развитии (в связи с исследованием взаимодействия познающего субъекта с познаваемым объектом) // Доклады АПН РСФСР. № 1. С. 73-77.

Пономарёв Я.А. (1960) Психология творческого мышления. М.: Изд-во Академии педагогических наук РСФСР.

Пономарёв Я.А. (1967) Знания, мышление и умственное развитие. М.: Педагогика.

Пономарёв Я.А. (1976а) Психология творчества. М.: Наука.

Пономарёв Я.А. (1976b). Психология творчества и педагогика. М.: Педагогика.

Пономарёв Я.А. (1983) Методологическое введение в психологию. М.: Наука.

Пономарёв Я.А. (2006) Перспективы развития психологии творчества // Психология творчества: школа Я.А. Пономарева. М.: Изд-во «Институт психологии РАН». C. $145-283$.

Пономарёв Я.А. (2010) Психика и интуиция. Неопубликованные материалы, стихи, рисунки и фотографии. М.: ООО «ТИД “Арис”». 
Пономарёв Я.А., Галкина Т.В., Кононенко М.А. (1997) Музыкальная одаренность: исследование общих компонентов // Когнитивное обучение: современное состояние и перспективы. М.: Институт психологии РАН. С. 95-114.

Пономарёв Я.А., Пастернак Н.А. (1995) Влияние способности действовать «в уме» на данные психологического тестирования // Психологический журнал. Т. 16. № 6. C. 43-54.

Хайкина М.В. (1998) Взаимосвязь между уровнем развития способности действовать «в уме» (СДУ) и особенностями развития речи и двигательных навыков: Дисс. ... канд. психол. наук. М.: Институт психологии РАН.

Хуснутдинова Л.Г. (1993) Исследование речемыслительной креативности личности: Дисс. ... канд. психол. наук. М.: Институт психологии РАН.

Галкина Татьяна Викторовна - кандидат психологических наук, доцент, старший научный сотрудник, лаборатория истории психологии и исторической психологии, ФГБУН «Институт психологии РАН», Россия, 129366, Москва, ул. Ярославская, д. 13/1; тел. +7(903)500-9567. E-mail: galkina@list.ru

Galkina Tatiana Victorovna - PhD (psychology), associate professor, senior research officer, laboratory of history of psychology and historical psychology; the Federal State-financed Establishment of Science, Institute of Psychology of Russian Academy of Sciences; 129366, Moscow, Yaroslavskaya str.13/1 Russia; E-mail: galkina@list.ru

\section{Для цитирования:}

Галкина Т.В. Научные представления Я.А. Пономарёва о центральном звене психологического механизма поведения и их развитие (к 100-летию со дня рождения учёного) // Научные труды Московского гуманитарного университета. 2020. №5. C. 13-26. DOI: https:// www.doi.org/10.17805/trudy.2020.5.2 